Editorial

\title{
Mexican Optics and Photonics Meeting 2012 - MOPM
}

San Luis Potosí, 19 al 21 de septiembre de 2012

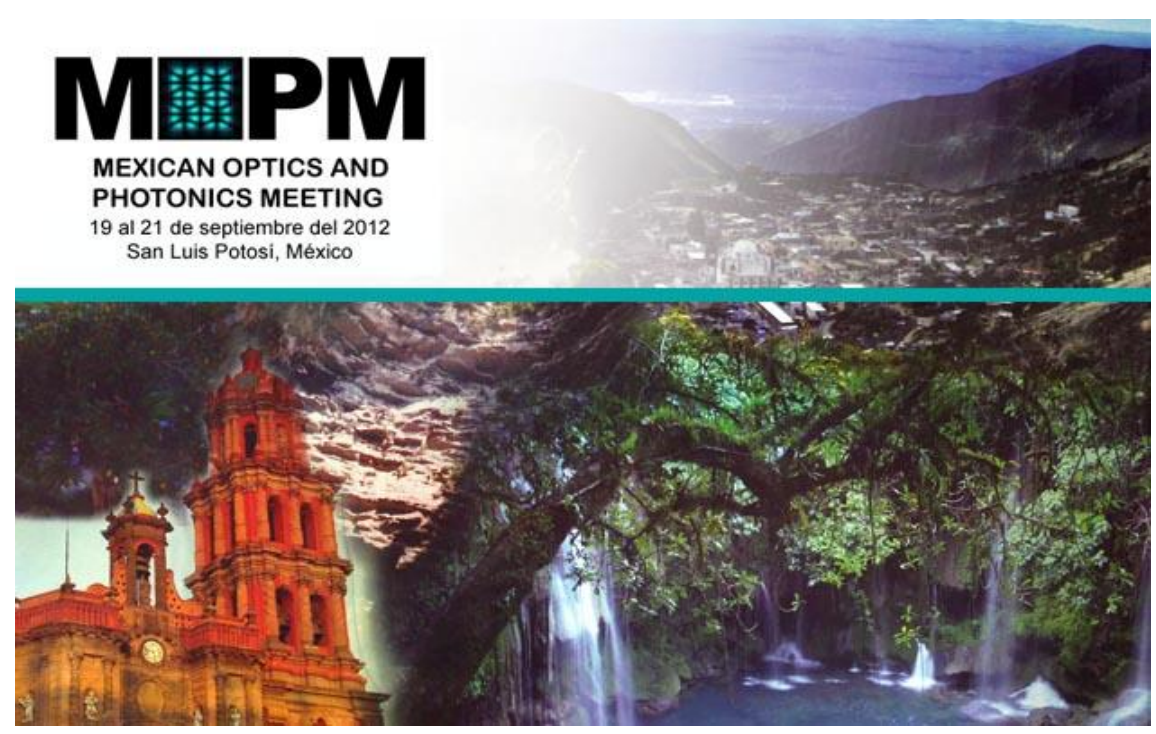

DOI: http://dx.doi.org/10.7149/0PA.46.1.i

Como parte de las celebraciones por su XXV aniversario, la Academia Mexicana de Óptica, A. C, (AMO) realizó la primera edición de la Mexican Optics and Photonics Meeting (MOPM) los pasados 19 al 21 de septiembre, en las instalaciones de la Unidad de Posgrados de la Universidad Autónoma de San Luis Potosí (UASLP), ubicada en las vecindades del Centro Cultural Bicentenario de esta casa de estudios.

La MOPM es una novedosa reunión que busca proyectar hacia el ámbito internacional, la investigación de alto nivel que se realiza en óptica y fotónica en México. Su formato, con duración de tres días, incluye la presentación de pláticas plenarias dictadas por científicos reconocidos internacionalmente; un número reducido de pláticas ofrecidas por oradores invitados; y una sesión mural donde se abre espacio para presentar contribuciones que son sometidas a un arbitraje estricto.

La MOPM 2012 fue extraordinariamente bien dirigida por el Dr. Alfonso Lastras Martínez, del Instituto de Investigación en Comunicación Óptica de la UASLP, y sirvió de inmejorable marco para que la AMO reconociera la destacada labor de sus doce socios fundadores, el liderazgo de sus diez ex presidentes y la enorme dedicación de sus ocho secretarios ejecutivos anteriores, en una ceremonia solemne especialmente realizada con esta finalidad.

Tres de las pláticas plenarias ofrecidas en la MOPM 2012 trataron tópicos de frontera en la óptica y fotónica: "A Century of Plasmonics", por David Aspnes de la North Carolina State University; "Atomic and Molecular Physics at the LCLS X-Ray Laser", por Phil Bucksbaum de Stanford University; y "Evanescent Fields in Nanofibers", por Luis Adolfo Orozco del Joint Quantum Institute de la University of Maryland y el National Institute for Standards and Technology; mientras que una más: "SISMENEC: $A$ Meeting Place for Industry, Consumers and Academia", por Francisco Ramos Gómez de la Universidad Nacional Autónoma de México, ofreció a los asistentes una propuesta interesante para incrementar el impacto económico y social de la investigación básica; y otra: "Linking Academia \& Business: The Experience of Industrias 
Tonaly", por Ricardo Benjamín Ávila Suárez de Industrias Tonaly, compartió sus experiencias dentro de una empresa de base tecnológica.

El programa técnico de la MOPM 2012 quedó complementado con las pláticas de veinte destacados investigadores que presentaron sus resultados más recientes y relevantes; dos sesiones murales en las que se presentaron setenta y cinco trabajos arbitrados; y dos cursos cortos: "Modulated Spectroscopies" y "Semiconductor Diodes Lasers".
La MOPM realizará su segunda edición, la MOPM 2013, del 4 al 6 de septiembre próximo en la ciudad de Ensenada, Baja California; con el apoyo del Centro de Investigación Científica y de Educación Superior de Ensenada; y será dirigida por el Dr. Raul Rangel.

Amalia Martínez García Eric Rosas

Por el Comité Organizador de la MOPM

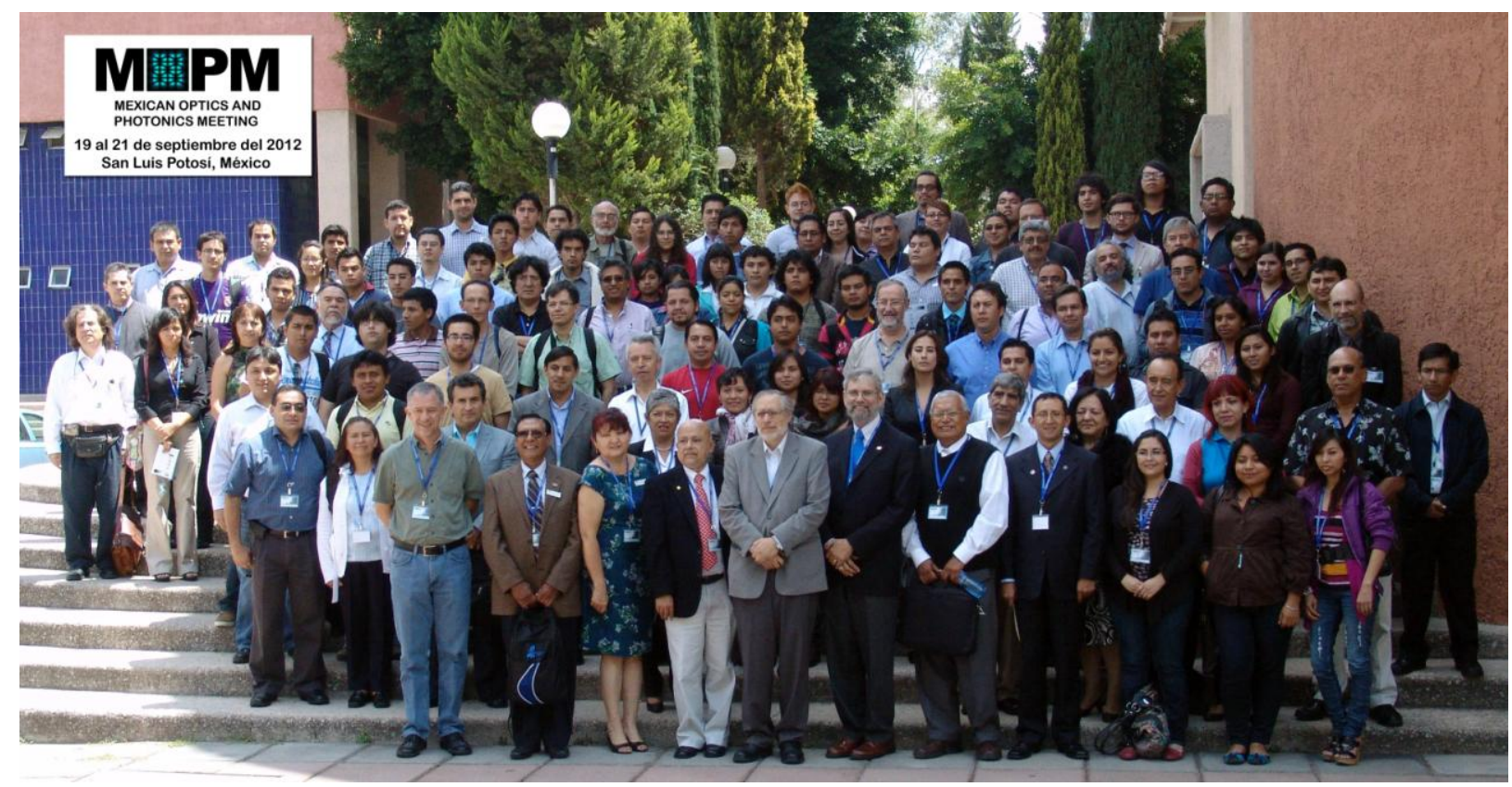

Fig. 1: Asistencia al MOPM2012. 